\title{
EuBrewNet - A European Brewer network (COST Action ES1207), an overview
}

\author{
John S. Rimmer ${ }^{1}$, Alberto Redondas ${ }^{2}$, and Tomi Karppinen ${ }^{3}$ \\ ${ }^{1}$ School of Earth and Environmental Sciences, University of Manchester, Manchester, M13 9PL, UK \\ ${ }^{2}$ Izaña Atmospheric Research Center, Agencia Estatal de Meteorología, Tenerife, Spain \\ ${ }^{3}$ Finnish Meteorological Institute, Arctic Research Center, Finland
}

Correspondence: Alberto Redondas (aredondasm@aemet.es)

Received: 20 December 2017 - Discussion started: 15 January 2018

Revised: 31 May 2018 - Accepted: 2 July 2018 - Published: 19 July 2018

\begin{abstract}
COST Action ES1207, EuBrewNet, was proposed to coordinate Brewer spectrophotometer measurements of ozone, spectral UV and aerosol optical depth (AOD-UV) in the UV within Europe, and unite the ozone, UV and AOD communities, through a formally managed European Brewer Network capable of delivering a consistent, spatially homogeneous European data resource. With emphasis on the ozone measurements, an overview is given of new calibration and instrument characterization procedures, which are then incorporated into new algorithms for the determination of total column ozone taking account of non-linearities and stray light effects within the spectrometer. A new near real time database is described where all raw data are processed centrally and subjected to the same quality control criteria. Data products are produced in levels that reflect the stages of quality control applied from initial near real time to final archive quality for trend analysis. Work is ongoing to complete similar procedures for the UV and AOD-UV data products. Governance of the new network, which has already expanded beyond the boundaries of Europe, will be overseen directly by the WMO Scientific Advisory Groups.
\end{abstract}

\section{Introduction}

Although our knowledge and understanding of the processes and reactions that affect ozone concentrations in the stratosphere have grown significantly in recent years, there are still uncertainties in the predictions of future trends and the quantification of the effects of policy measures to protect the ozone layer. There is also a growing recognition that the is- sues of stratospheric ozone depletion and of climate change are closely linked (Hossaini et al., 2015; McKenzie et al., 2011) and that climate change will influence the recovery of the ozone layer (see also: WMO/UNEP Scientific Assessments of Ozone, https://www.esrl.noaa.gov/csd/assessments/ ozone/, last access: 10 July 2018; United Nations Environment Programme, Environmental Effects Assessment Panel, 2010). Therefore, long-term monitoring continues to be essential to provide the necessary feedback into predictions on the recovery of the stratosphere.

The unprecedented depletion of the Arctic ozone layer in spring 2011 (Manney et al., 2011) served as a stark reminder that, 24 years after the Montreal Protocol, our understanding of global and local trends in stratospheric ozone (Chipperfield et al., 2017; Weber et al., 2018) is still important. The corresponding significant increases in UV radiation over large areas of northern Europe were clearly cause for concern. In addition to ozone, aerosols and clouds affect the UV radiation and usefully accurate forecasts also must take account of these factors. The challenge remains to improve the accuracy and understanding of the relationships between UV radiation, ozone, clouds and aerosols. Furthermore, although the ozone variations have been considered mainly for their effect on the ultraviolet radiation, it should be kept in mind that ozone, even if in a small abundance in the atmosphere, plays a key role in the energy balance of the planet through its involvement in radiative processes. Ozone changes may have lasting consequences within the climate system.

While satellites are routinely used to retrieve atmospheric data products, their accuracy is underpinned by ground station measurements. Once launched, drifts in calibration or 
errors due to snow or cloud albedo, can only be detected by comparison with ground station data. Spectral UV irradiance products derived from satellite instruments are entirely estimated, based on radiative transfer models and the retrieved total ozone column (TOC), and they are far from representing the actual radiation field at a specific ground location (Zempila et al., 2016), particularly under cloudy conditions or at heavily polluted environments. As is particularly true whenever long-term trends are of interest, the fundamental responsibility to define the limits of accuracy therefore rests with the ground station instruments.

The fully automated Brewer spectrophotometer (Kerr et al., 1985; Brewer MKIII Operator's Manual, 2015) is slowly supplanting its predecessor, the Dobson ozone spectrophotometer, has provided high quality TOC data for more than 30 years and is now deployed at most of the ground based TOC monitoring stations in Europe. It is also capable of measurements of ozone vertical profiles (Umkehr method), spectral UV radiation and aerosol optical depth in the UV (AODUV), as well as columns of other trace constituents such as sulfur dioxide and nitrogen dioxide. There are over two hundred Brewers deployed throughout the world, independently operated by national agencies, of which around fifty are located within Europe (some since the early 1980s). This represents not only a significant proportion of the total global monitoring effort, but also an extremely valuable resource of co-located TOC, UV and AOD-UV measurements which was previously being considerably underused due to the lack of coordination and harmonization between the respective agencies. The co-location of these measurements is crucial for providing consistent data for research into radiative transfer and forecasting models' however, any operational disparity serves to severely restrict the overall utility. The aim of COST Action ES1207 was to facilitate the harmonization of procedures and therefore provide spatially consistent data.

Disparity arises since each station may pursue differing measurement schedules which may not contribute to a coordinated outcome. Furthermore, data processing methods vary such that different agencies may arrive at different results from the same raw data file which in some cases may exceed the $1 \%$ level of accuracy which is currently sought. Effects of instrument characteristics on the derived products may be handled differently if, indeed, they are handled at all and quality control methods also vary from site to site. For example, any slowly varying change in the instrument spectral response would lead to a "false" trend in the data over time or stray light effects in single spectrometer Brewers would cause highly significant errors in daily mean values unless measurements were restricted to low air mass factors. In addition, there have been no protocols to govern updates to software or experimentally determined physical constants. Although the Regional Brewer Calibration Centre - Europe (RBCC-E) has been in place providing support for a first generation (derived from stable atmosphere Langley plots rather than transfer) calibrated Brewer reference triad on TOC for several years, there are no mandatory and clear protocols for frequency and retro-application of calibration data. The wellreputed services of the World Ultraviolet Calibration Centre (WUVCC) have also been underused, with too few stations participating to guarantee the homogeneity of time series on spectral UV. In short, there has been no formal European Brewer network and related regional data base capable of providing spatially consistent data to a high degree of accuracy with a common scale of quality assurance. This is not to say that previous Brewer data cannot be trusted for serious scientific study. In fact, the majority of measurement stations have been providing high quality data for many years and the more experienced operatives have been quick to offer assistance to the less well versed or newly set up observatories, particularly in the developing world (e.g. the WMO/GAW Brewer Users Group workshops organized by Environment Canada). EuBrewNet is a first step in trying to bring everything into alignment as more exacting demands are placed on our data analysis.

\section{Characterization and calibrations}

The first step in ensuring consistency is to set standards for observational quality. Individual instruments must therefore be characterized to establish how component characteristics, e.g. slit function (measured directly using $\mathrm{Hg}$ and Cd sources), wavelength calibration (Redondas et al., 2014b, 2018a), photomultiplier tube (PMT) linearity (Fountoulakis et al., 2016), spectral responsivity, temperature dependence (Berjón et al., 2018; Fountoulakis, 2017), stray light (Karppinen et al., 2015; Pulli et al. 2016; Redondas et al. 2017), field of view, angular response and polarization (Carreño et al., 2016) uniquely affect measurement outcomes and how potential errors may be avoided or corrected for.

In addition, measurement accuracy is ultimately dependent on regular and accurate calibration. Methodologies which ensure the best transfer of calibration constants and traceability to the reference laboratories, these being the RBCC-E triad for total ozone, the World Ultra-Violet Calibration Centre (WUVCC) and the Quality Assurance of solar Spectral Ultraviolet irradiance Measurements carried out in Europe (QASUME; Gröbner and Sperfeld, 2005) for the UV measurements, either have been or are being developed. Regular comparison with the Canadian Brewer Triad is also maintained to ensure global compatibility of TOC measurements (León-Luis et al., 2018). In order to ensure a traceable laboratory characterization of the reference Brewer instruments, the reference RBCC-E (Regional Brewer Calibration Center for Europe) Brewer from the calibration triad from the Spanish Meteorological Agency at Izaña and the travelling reference Brewer \#158 from the manufacturer Kipp $\&$ Zonen were thoroughly characterized for temperature dependency, wavelength bandwidth and stray light in 2016 and 2017 respectively on the frame of the ENV59 Traceability 
for atmospheric total column ozone (ATMOZ) project. The instruments were characterized using a dedicated climate chamber and tunable laser facilities at the National Metrology Institutes. In the ATMOZ project, participants included the metrology institutes of Finland, Czech Republic, Germany, Netherlands and Switzerland. The temperature experiment was performed by the Physikalisch-Technische Bundesanstalt, PTB (Germany) and Netherlands (VSL) National Metrology Institute and the wavelength calibration was performed at PTB (Redondas et al., 2018a). Filter and stray light characterization were performed by Aalto (Finland) (Pulli et al., 2018).

The results confirmed the existing understanding and correction of the temperature dependence of Brewer instruments to properly estimate and to reduce the uncertainty of ozone retrieval with Brewers (Redondas et al., 2016; Berjón et al., 2017). Also a preliminary error estimation was developed (Egli et al., 2016) with the objective to implement on the Eubrewnet database.

\section{Central data processing}

For each ozone value five quasi-simultaneous observations are made. Each observation consists of 20 cycles of quasi-simultaneous measurements of intensity at five UVwavelengths by fast switching of the spectrometer exit slit mask. Wavelengths are instrument specific but nominally $306.3,310.1,313.5,316.8$ and $320.1 \mathrm{~nm}$. Intensities are written to a raw file for further processing. Raw data are transferred automatically every $30 \mathrm{~min}$ from each Brewer on the network to the new EuBrewNet database, hosted by the Agencia Estatal Meteorologia (AEMET).

The algorithm to retrieve TOC from individual observations is based on differential absorption of ozone at the measured wavelengths and has been described several times (De Backer and De Muer, 1991; Savastiouk and McElroy, 2005). A simplified description is given here in order to illustrate the improvements implemented through EuBrewNet.

A weighted double ratio, $\mathrm{R} 6\left(\mathrm{O}_{3}\right)$, of the measured intensities is calculated and compared to the similar extra-terrestrial double ratio, $\mathrm{ETC}_{0}$, determined by transfer from a travelling reference instrument. The weighting coefficients are designed to minimize the effects of aerosols and $\mathrm{SO}_{2}$ spectral absorption. A differential absorption coefficient, $\alpha$, corresponding to this ratio, is calculated from ozone absorption cross sections convoluted with the slit functions at the measurement wavelengths and is used to transform this difference into total ozone on the light path or slant column. To get the vertical total ozone column, $\mathrm{O}_{30}$, the value is further divided by air mass factor $\mu$ (Eq. 1).

$\mathrm{O}_{30}=\frac{\mathrm{R} 6\left(\mathrm{O}_{3}\right)-\mathrm{ETC}_{0}}{\mu \alpha}$
The next step is to apply corrections to the level 0 data, $\mathrm{O}_{30}$, based on the instrument characterization where available. A current controlled halogen lamp located inside the Brewer is used to track instrument response stability. Measurements of the lamp to produce a similar weighted double ratio, $\mathrm{R} 6(\mathrm{SL})$, are compared to a reference, $\mathrm{R} 6_{\text {ref }}$, taken at the time of calibration and used to apply a correction $\Delta_{\mathrm{SL}}$ to the measured ozone data (Eq. 2).

$\Delta_{\mathrm{SL}}=\frac{\mathrm{R}_{\mathrm{ref}}-\mathrm{R} 6(\mathrm{SL})}{\mu \alpha}$

A series of neutral density filters are present in the input optics of the Brewer and these are characterized for nonlinearities, $\mathrm{ETC}_{\mathrm{N}}$, by observing changes in instrument response via the calculated ratio, R6(SL), as filters are changed, so that a filter dependent correction, $\Delta_{\text {Filter }}$ can also be applied (Eq. 3).

$\Delta_{\text {Filter }}=\frac{\text { ETC }_{\mathrm{N}}}{\mu \alpha}$

Finally, a stray light correction is applied to the single Brewers where this has been characterized. The characterization is based on an exponential fit between single and double Brewer measurements (Karppinen et al., 2015; Redondas et al., 2018b; Redondas et al., 2018b). The correction is an iterative process resulting in bringing the single Brewer values into agreement with the double Brewers, as shown in the example of Fig. 1, even at low solar elevation angles (Eq. 4). $N$ in Eq. (4) is the iteration index, where the first iteration is performed on the uncorrected ozone value and the corrected value is then inserted back into the equation $N$ times until the result converges

$\Delta_{\text {Straylight }, N}=\frac{A \cdot\left(\mu \mathrm{O}_{3, N-1}\right)^{B}}{\mu \alpha}$

The constants $A$ and $B$ are determined during the characterization process. The resulting ozone value is given by combining Eqs. (1)-(4).

$\mathrm{O}_{3}=\mathrm{O}_{30}+\Delta \mathrm{O}_{3 \mathrm{SL}}-\Delta \mathrm{O}_{3 \text { Filter }}-\Delta \mathrm{O}_{3 \text { Straylight }}$

Finally the data are filtered to select only those measurements that conform as follows: for the ozone product, the standard deviation of the five quasi-simultaneous ozone measurements must be less than 2.5 Dobson units (DU), the air mass factor must be less than 3.5 (this can be set higher for MKIII double Brewers or where stray light correction has been applied), there must be a valid mercury lamp wavelength calibration before and after the measurement such that the difference between the two does not exceed three steps of the spectrometer micrometre drive $(\sim 0.02 \mathrm{~nm})$ and the measured ozone value must be between $100 \mathrm{DU}$ and $500 \mathrm{DU}(\mathrm{al}-$ though this may be edited by the data provider if necessary, e.g. 600 DU may sometimes be observed in Sodankylä). The 


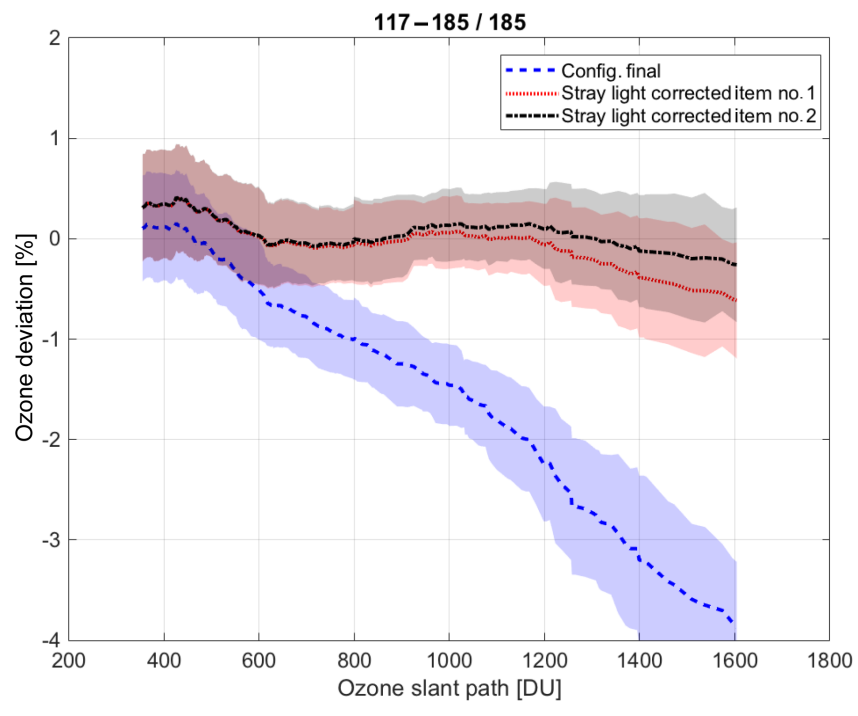

Figure 1. A comparison of a single Brewer, \#070, with the RBCCE reference Brewer, \#185, showing stray light correction. The blue and red lines are the initial ozone deviation of \#070 from the reference, before and after calibration. The black line shows the stray light corrected values.

AOD-UV data product is described elsewhere (López-Solano et al., 2018) and will be implemented within EuBrewNet in the coming months. Similarly, work is underway to develop the calibration protocols and processing for the UV data (Lakkala et al., 2016).

\section{The EuBrewNet near real time database}

Figure 2 is a recent snapshot of the EuBrewNet network which is constantly growing. A real time updated version can be found at http://rbcce.aemet.es/eubrewnet (last access: 10 July 2018). The core of EuBrewNet is a data storage and scientific information processing system for the Brewer spectrophotometers (http://rbcce.aemet.es/eubrewnet) to which the Brewer raw data are automatically transferred on a halfhourly basis. The data are then processed in near real time (NRT) as described above in Sect. 3. A schematic of the data stream and processing is shown in Fig. 3.

The calibration and characterization data for each instrument must also be stored in the database which will then allow the raw data to be converted into data products in near real time (NRT). The raw data are also uploaded to WOUDC for long term data archiving and back up. The output of ozone products is now operational and these are accessible from the EuBrewNet database. A similar methodology is being developed for the Brewer UV and aerosol optical depth products which should be available in the near future.

The data products are produced at different levels.

- Level 0. Raw data from the Brewer. This is the unprocessed data that is only available to the providing oper- ator so that appropriate diagnostic checks can be made to check data on a regular basis.

- Level 1.0. Basic values from calibration data calculated using Eq. (1). This is the most basic ozone product, without any QA or corrections applied, equivalent to the calculation made by the Brewer control software on site. This enables a comparison to be made to check that the correct calibration data are being used.

- Level 1.5. NRT data changeable over the first week. Calibration and characteristic corrections applied as in Eqs. (2)-(5). This is the first data product available to the registered users. The data are passed through a series of filters, and corrections are applied based on the instrument characterization and the stability checks by the internal standard lamp. The standard lamp correction is applied using a triangular weighted smoothing 3 days before and after the day of the measurement. This means that L1.5 data can change as more QA information becomes available. This NRT data are most useful for assimilation into forecast models.

- Level 1.6. Interim data with calibration and characteristic corrections applied. Available to users, this is simply L1.5 data once the standard lamp correction has been fully applied and the value is now stable. This data are most useful for the interim values normally used for day to day reporting.

- Level 2.0. This is the final processed data for archiving, interpolated over a calibration cycle and also available to users. To comply with WMO best practice, Brewers should be calibrated every 2 years. The procedure is to first check the status of the calibration, second to do any maintenance and lastly to set the final calibration. If the initial status of the calibration does not agree with the final calibration of the previous intercomparison, this indicates instrument drift and the ozone values must be re-calculated based on the interpolation between the two points. The resulting L2 data are the highest quality that can then be archived and used for trend analysis.

In addition to levels, the database also stores multiple versions, each containing its own levels as described above. For example, Version 1 contains ozone data using Bass and Paur ozone cross sections. However, the International Ozone Commission recently wrote to the WMO SAG-Ozone directing them to implement the new Bremen cross sections, and also to take stratospheric temperature into account. EuBrewNet makes this easy by re-processing all the data in the data base using the new cross sections and storing it as Version 2, also retaining Version 1, in parallel, for the historical record. A study on the effects of using different ozone cross sections has been carried out previously (Redondas et al., 2014a). 


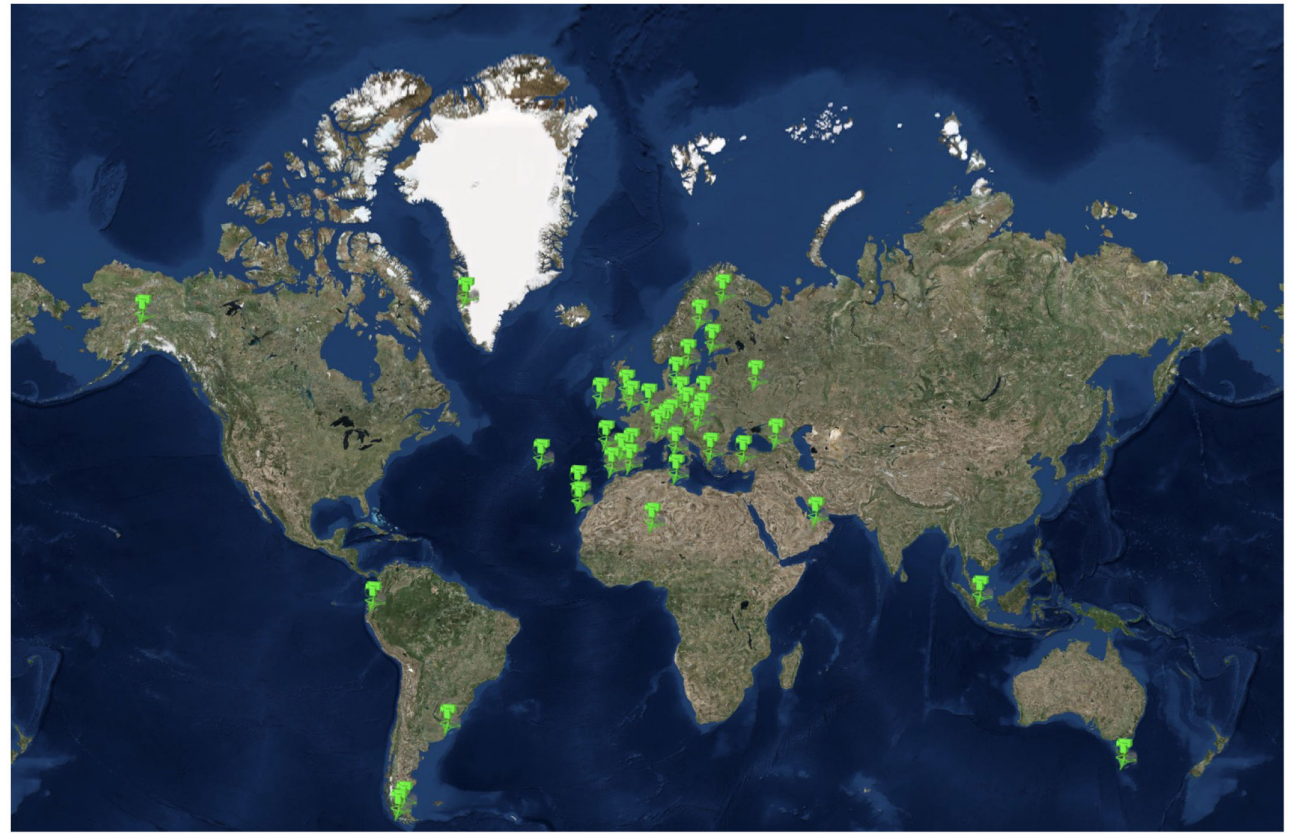

Figure 2. A snapshot of the Brewer stations contributing to EuBrewNet (10 July 2018).

The idea is that all these data products will be available directly via a link with the WOUDC so that users do not need to go to a different data base. However, this link is still under construction under the supervision of a sub-group of the WMO SAG-Ozone. For the moment, users may register to access data at http://rbcce.aemet.es/eubrewnet, which includes a wiki that contains information about the system and user support (Redondas et al., 2018c), and further information including instructions on how to contribute to the network can be found at http://www.eubrewnet.org (last access: 10 July 2018).

\section{Regional Calibration Centre for Europe (RBCC-E)}

The RBCC-E campaigns and regular calibration play an important role on the final data (Level 2), as is indicated in Eq. (2), the operative ozone is corrected by the standard lamp, the standard lamp reference value is provided during the calibration and examined during the intercomparison campaign (Redondas et al., 2018b). The previous calibration and new calibration are compared with and without the standard lamp correction to assure that the internal standard lamp is tracking the changes on calibration.

As a result of the calibration the validity of the current calibration is examined during the campaign and if a new calibration is provided, the history of the instrument is studied to determine from when the observations have to be reprocessed using a step function or if the changes are continuous and linear evolution of the instrument calibration are implemented between calibrations. In both cases comparison with

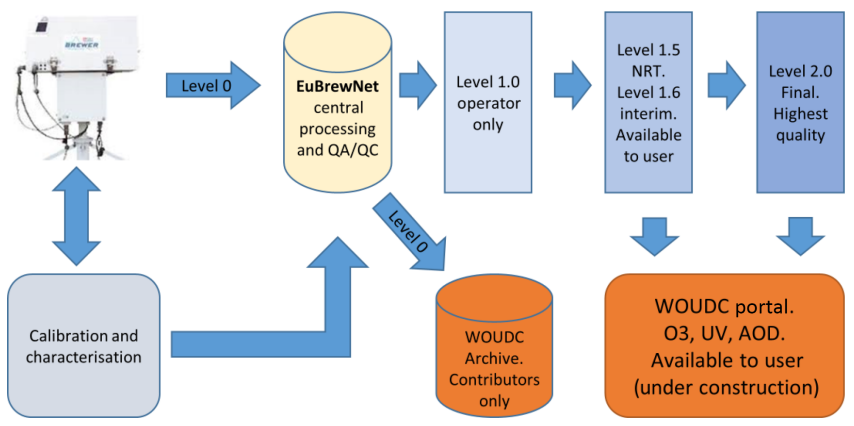

Figure 3. Schematic of the EuBrewNet near real time database.

external instruments, neighbouring Brewer or satellite overpass measurements, will help to evaluate the application of these functions.

The campaigns also help on the characterization of the instruments, the comparison with a well maintained and characterized instrument reveals instrumental characteristics that are difficult to detect at the station without a reference. In particular the filter correction and the stray light (Fig. 1).

The introduction of the instrumental characterization greatly improves the results of the TOC intercomparison (Redondas and Rodriguez, 2012), in particular the stray light correction application at the final calibration brings all the instrument to within $\pm 0.5 \%$ (Redondas et al., 2018b) on the full range. In the future it is hoped that similar achievements can be made for the UV and AOD-UV products. 


\section{Conclusions}

COST Action ES1207, "EuBrewNet - A European Brewer Network", was awarded to allow the harmonization and coordination of Brewer ozone spectrophotometer measurements of TOC, spectral UV and AOD-UV. New instrument characterization methodologies have been implemented and calibration campaigns have been carried out which use these new methodologies to greatly improve the accuracy of the results. Common data processing and quality assurance also now ensure consistency of measurements throughout the network.

A major part of EuBrewNet is the new NRT database, which automatically collects raw data from the instruments and applies the new data processing and quality assurance centrally, thereby ensuring the consistency of the resulting data products across the network. Currently, the TOC processing is in operation and NRT data are available to registered users. The AOD-UV processing algorithms have been developed but are yet to be implemented. Similarly the UV processing is still under development but should be implemented in the early part of 2018.

A link to the WOUDC is currently under construction so that data will be available through a portal at the WOUDC web site. The Brewer raw data are also transferred to the WOUDC for long term archiving. Governance of the EuBrewNet is to be overseen by the WMO SAG Ozone.

Further details of EuBrewNet and registration for data are available at the web site http://www.eubrewnet.org and more specific technical details are available from the EuBrewNet wiki at http://rbcce.aemet.es/dokuwiki/doku.php (last access: 10 July 2018).

Data availability. The observations, model and programming codes used on EUBREWNET are available at the EUBREWNET website (http://eubrewnet.org/).

Author contributions. JR, Chairman of EUBREWNET COST action, led the manuscript preparation. AR, Vice Chairman of EUBREWNET COST action, contributed to the manuscript. TK, lead of the Algorithm working group of EUBREWNET and contributed to the manuscript.

Competing interests. The authors declare that they have no conflict of interest.

Special issue statement. This article is part of the special issue "Quadrennial Ozone Symposium 2016 - Status and trends of atmospheric ozone (ACP/AMT inter-journal SI)". It is a result of the Quadrennial Ozone Symposium 2016, Edinburgh, United Kingdom, 4-9 September 2016.
Acknowledgements. The authors would like to acknowledge networking support by the COST Action ES1207, and contributions from the Regional Brewer Calibration Centre for Europe and the World Radiation Centre. The authors also acknowledge the considerable support from all the working group members of COST Action ES1207, who contributed significantly to the project.

Edited by: Irina Petropavlovskikh

Reviewed by: three anonymous referees

\section{References}

Berjón, A., Redondas, A., Sildoja, M.-M., Nevas, S., Wilson, K., León-Luis, S. F., el Gawhary, O., and Fountoulakis, I.: Sensitivity study of the instrumental temperature corrections on Brewer total ozone column measurements, Atmos. Meas. Tech., 11, 33233337, https://doi.org/10.5194/amt-11-3323-2018, 2018.

Brewer MKIII Operator's Manual: available at: www.kippzonen. com/Download/207/Brewer-MkIII-Operator-s-Manual (last access: 10 July 2018), 2015.

Carreño, V., Diémoz, H., León-Luis, S. F., López-Solano, J., Hernández-Cruz, B., Berjón, A., Santana-Díaz, D., Rodríguez Valido, M., and Redondas, A.: Brewer direct irradiance measurements: polarization effects and model simulation, Edinburgh, UK, available at: http://presentations.copernicus.org/ QOS2016-225_presentation.pdf (last access: 10 July 2018), 2016.

De Backer, H. and De Muer, D.: Intercomparison of total ozone data measured with Dobson and Brewer ozone spectrophotometers at Uccle (Belgium) from January 1984 to March 1991, including zenith sky observations, J. Geophys. Res.-Atmos., 96, 2071120719, 1991.

Egli, L., Gröbner, J., Köhler, U., Redondas, A., Carreño, V., and Diemoz, H.: A simulation-tool to model ozone retrieval uncertainties of Brewer and Dobsons instruments, UVNews, 11, 3641, available at: http://metrology.tkk.fi/uvnet/source/UVNews_ 11.pdf (last access: 10 July 2018), 2016.

Fountoulakis, I., Redondas, A., Bais, A. F., Rodriguez-Franco, J. J., Fragkos, K., and Cede, A.: Dead time effect on the Brewer measurements: correction and estimated uncertainties, Atmos. Meas. Tech., 9, 1799-1816, https://doi.org/10.5194/amt-9-1799-2016, 2016.

Fountoulakis, I., Redondas, A., Lakkala, K., Berjon , A., Bais, A. F., Doppler, L., Feister, U., Heikkila, A., Karppinen, T., Karhu, J. M., Koskela, T., Garane, K., Fragkos, K., and Savastiouk, V.: Temperature dependence of the Brewer global UV measurements, Atmos. Meas. Tech., 10, 4491-4505, https://doi.org/10.5194/amt-10-4491-2017, 2017.

Gröbner, J. and Sperfeld, P.: Direct traceability of the portable QASUME irradiance scale to the primary irradiance standard of the PTB, Metrologia, 42, 134, https://doi.org/10.1088/00261394/42/2/008, 2005.

Hossaini, R., Chipperfield, M. P., Montzka, S. A., Rap, A., Dhomse, S., and Feng, W.: Efficiency of short-lived halogens at influencing climate through depletion of stratospheric ozone, Nat. Geosci., 8, 186-190, 2015.

Karppinen, T., Redondas, A., García, R. D., Lakkala, K., McElroy, C. T., and Kyrö, E.: Compensating for the Effects of Stray Light 
in Single-Monochromator Brewer Spectrophotometer Ozone Retrieval, Atmos. Ocean, 53, 66-73, 2015.

Kerr, J. B., McElroy, C. T., Wardle, D. I., Olafson, R. A., and Evans, W. F. J.: The Automated Brewer Spectrophotometer, in: Atmospheric Ozone, edited by: Zerefos C. S. and Ghazi, A., Springer, Dordrecht, the Netherlands, 1985.

Lakkala K., León-Luis, S. F., Redondas, A., Hermández, B., Karppinen, T., and Arola, A.: UV Configuration and Processing in the EUBREWNET, COST ES1207, Brewer Ozone Spectrophotometer/Metrology Open Workshop, 17-20 May 2016, Azores, Portugal, 2016.

León-Luis, S. F., Redondas, A., Carreño, V., López-Solano, J., Berjón, A., Hernández-Cruz, B., and Santana-Díaz, D.: Internal consistency of the Regional Brewer Calibration Centre for Europe triad during the period 2005-2016, Atmos. Meas. Tech., 11, 4059-4072, https://doi.org/10.5194/amt-11-4059-2018, 2018.

López-Solano, J., Redondas, A., Carlund, T., Rodriguez-Franco, J. J., Diémoz, H., León-Luis, S. F., Hernández-Cruz, B., GuiradoFuentes, C., Kouremeti, N., Gröbner, J., Kazadzis, S., Carreño, V., Berjón, A., Santana-Díaz, D., Rodríguez-Valido, M., De Bock, V., Moreta, J. R., Rimmer, J., Smedley, A. R. D., Boulkelia, L., Jepsen, N., Eriksen, P., Bais, A. F., Shirotov, V., Vilaplana, J. M., Wilson, K. M., and Karppinen, T.: Aerosol optical depth in the European Brewer Network, Atmos. Chem. Phys., 18, 38853902, https://doi.org/10.5194/acp-18-3885-2018, 2018.

Manney, G. L., Santee, M. L., Rex, M., Livesey, N. J., Pitts, M. C., Veefkind, P., Nash, E. R., Wohltmann, I., Lehmann, R., Froidevaux, L., Poole, L. R., Schoeberl, M. R., Haffner, D. P., Davies, J., Dorokhov, V., Gernandt, H., Johnson, B., Kivi, R., Kyrö, E., Larsen, N., Levelt, P. F., Makshtas, A., McElroy, C. T., Nakajima, H., Parrondo, M. C., Tarasick, D. W., von der Gathen, P., Walker, K. A., and Zinoviev, N. S.: Unprecedented Arctic ozone loss in 2011, Nature, 478, 469, https://doi.org/10.1038/nature10556, 2011.

McKenzie, R. L., Aucamp, P. J., Bais, A. F., Bjorn, L. O., Ilyas, M., and Madronich, S.: Ozone depletion and climate change: impacts on UV radiation, Photoch. Photobio. Sci., 10, 182-198, 2011.

Pulli, T., Karppinen, T., Nevas, S., Kärhä, P., Lakkala, K., Karhu, J. M., Sildoja, M., Vaskuri, A., Shpak, M., Manoocheri, F., Doppler, L., Gross, S., Mes, J., and Ikonen, E.: Out-ofRange Stray Light Characterization of Single-Monochromator Brewer Spectrophotometers, Atmosphere-Ocean, 56, 1-11, https://doi.org/10.1080/07055900.2017.1419335, 2018.

Redondas, A.: Eubrewnet, available at: http://rbcce.aemet.es/ eubrewnet/, last access: 10 July 2018.

Redondas, A. M. and Rodriguez, J. J.: Regional Brewer Calibration Center - Europe CEOS campaigns: Instrumental Findings, Quadrennial Ozone Symposium 2012 (QOS 2012), 27-31 August 2012, Toronto, Canada, ID:6166, 2012.
Redondas, A., Evans, R., Stuebi, R., Köhler, U., and Weber, M.: Evaluation of the use of five laboratory-determined ozone absorption cross sections in Brewer and Dobson retrieval algorithms, Atmos. Chem. Phys., 14, 1635-1648, https://doi.org/10.5194/acp-14-1635-2014, 2014a.

Redondas, A., Fountoulakis, I., Carreño Corbella, V., Franco, R., and José, J.: Dispersion test results with multiple geometries at RBCC-E campaign AROSA 2014, available at: https://repositorio.aemet.es/bitstream/20.500.11765/2604/1/ DSP_AROSA_2014.pdf (last access: 10 July 2018), 2014b.

Redondas, A., Berjón, A., Sildoja, M., Nevas, S., and Rodríquez, M.: Analysis of Brewer instrumental temperature dependence, UV News, 11, 8-19, http://metrology.tkk.fi/uvnet/reports.htm (last access: 10 July 2018), 2016.

Redondas, A., Nevas, S., Berjón, A., Sildoja, M.-M., León-Luis, S. F., Carreño, V., and Santana-Díaz, D.: Wavelength calibration of Brewer spectrophotometer using a tunable pulsed laser and implications to the Brewer ozone retrieval, Atmos. Meas. Tech., 11, 3759-3768, https://doi.org/10.5194/amt-11-3759-2018, 2018 a.

Redondas, A., Carreño, V., León-Luis, S. F., Hernández-Cruz, B., López-Solano, J., Rodriguez-Franco, J. J., Vilaplana, J. M., Gröbner, J., Rimmer, J., Bais, A. F., Savastiouk, V., Moreta, J. R., Boulkelia, L., Jepsen, N., Wilson, K. M., Shirotov, V., and Karppinen, T.: EUBREWNET RBCC-E Huelva 2015 Ozone Brewer Intercomparison, Atmos. Chem. Phys., 18, 9441-9455, https://doi.org/10.5194/acp-18-9441-2018, 2018 b.

Redondas, A., Hernández-Cruz, B., Berjón, A., López-Solano, J., Léon-Luis, S., and Fountoulakis, I.: [Eubrewnet Wiki], Eubrewnet Documentation, available at: http://rbcce.aemet.es/ dokuwiki/doku.php, last access: 10 July $2018 \mathrm{c}$.

Rimmer, J., Redondas, A., Groebner, J., Karppinen, T., De Bock, V., and Bais, A.: EUBREWNET, COST1207, available at: http: //eubrewnet.org/, last access: 10 July 2018.

Savastiouk, V. and McElroy, C. T.: Brewer spectrophotometer total ozone measurements made during the 1998 Middle Atmosphere Nitrogen Trend Assessment (MANTRA) campaign, Atmos. Ocean, 43, 315-324, 2005.

United Nations Environment Programme, Environmental Effects Assessment Panel: Environmental effects of ozone depletion and its interactions with climate change: progress report, 2009, Photochem. Photobiol. Sci., 9, 275-294, https://doi.org/10.1039/B923342N, 2010.

Zempila, M.-M., Koukouli, M.-E., Bais, A., Fountoulakis, I., Arola, A., Kouremeti, N., and Balis, D.: OMI/Aura UV product validation using NILU-UV ground-based measurements in Thessaloniki, Greece, Atmos. Environ., 140, 283-297, 2016. 